\title{
Synthesis of $(+)$-Cortistatin A
}

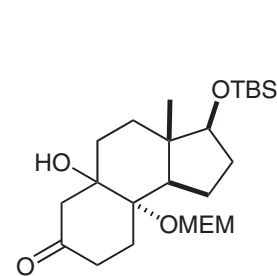

A

9 steps from the Hajos-Parrish keton
1. $\mathrm{SOCl}_{2}, \mathrm{py}, \mathrm{CH}_{2} \mathrm{Cl}_{2},-10^{\circ} \mathrm{C}$ 2. $\mathrm{NaHMDS}, \mathrm{PhNTf}_{2}, \mathrm{THF}, 0^{\circ} \mathrm{C}$

3. B, $\mathrm{Pd}\left(\mathrm{PPh}_{3}\right)_{4}$, THF, r.t.

4. $\mathrm{CHBr}_{3}, t$-BuOK, hexane, $0{ }^{\circ} \mathrm{C}$

5. TASF, DMF, $80^{\circ} \mathrm{C}$

$$
41 \%
$$

Negishi coupling

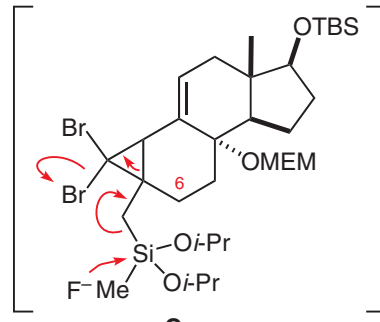

C<smiles>[M]OC12CCC(=C)C(C)(C)CC=C1CCC2[OH2+]</smiles>

\section{aza-Prins}

cyclization

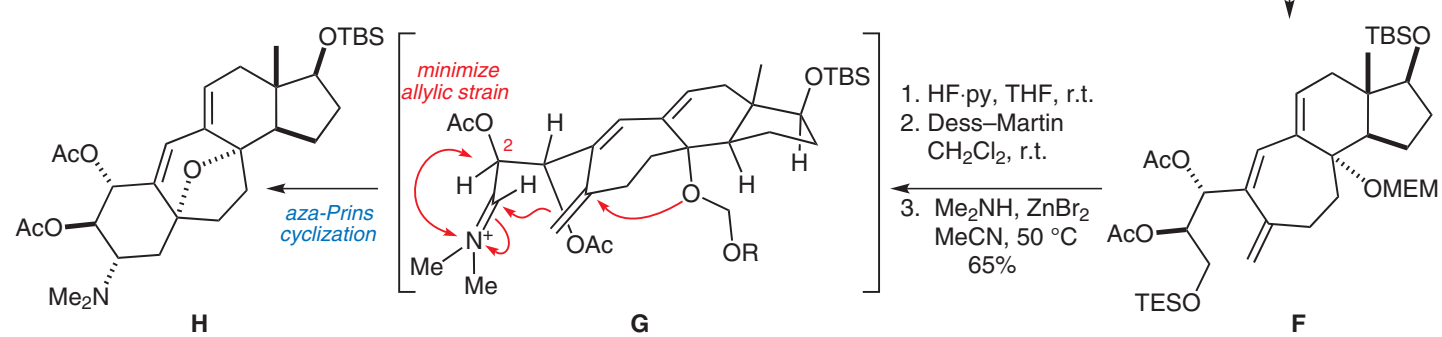

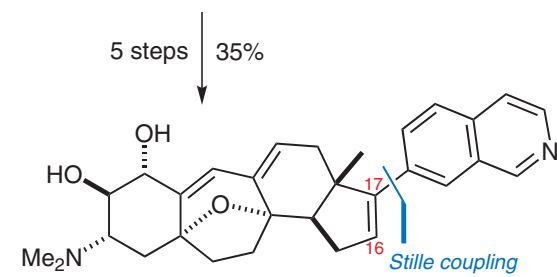

I

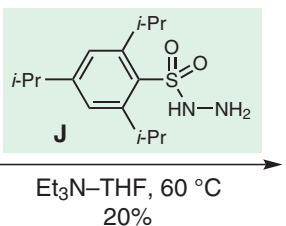

$20 \%$

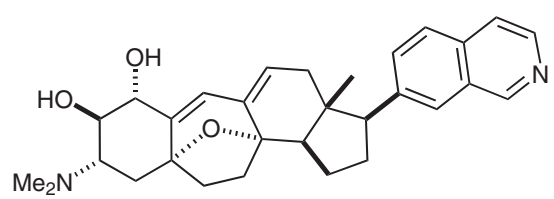

(+)-Cortistatin A 17 steps, $0.8 \%$ from $\mathbf{A}$
Significance: Cortistatin A was isolated together with structurally related molecules from the sponge Corticium simplex. It shows potent antiangiogenetic activity with a high selectivity towards several human and murine cancer cell lines. The focal step of the synthesis is a highly stereoselective aza-Prins cyclization to complete the steroid-like carbon framework $(\mathbf{G} \rightarrow \mathbf{H})$.
Comment: Thermal loss of bromide from $\mathbf{C}$ and cyclopropyl opening followed by fluoride-induced desilylation of the resulting pentadienyl cation leads to vinyl bromide D. Using the less electrophilic TMS group gave a cycloheptadiene via deprotonation at $\mathrm{C} 6$ by fluoride. Hydrogenation of the C16/C17 double bond in I could only be achieved in low yield using diimide generated from $\mathbf{J}$.

sYNFacts Contributors: Philip Kocienski, Arndt W. Schmidt DoI: 10.1055/s-0029-1216673; Reg-No.: K05209SF 